\title{
A Brief Analysis of Communicative Translation and Semantic Translation Mingyue $\mathrm{Zu}^{1,}$, Yang Dong ${ }^{2, \mathrm{~b}}$ \\ ${ }^{1}$ School of Applied English, Beijing International Studies University, Beijing, China; \\ ${ }^{2}$ School of Applied English, Beijing International Studies University, Beijing, China. 81509608@qq.com*,1359819638@qq.com
}

Keywords: communicative translation; semantic translation; translating practice

\begin{abstract}
This paper aims at facilitating translating practice by reinterpreting Peter Newmark's theory from a different linguistic viewpoint blending with cultural factors. The research methods adopted in the paper include literature review, comparison and case study. Communicative translation and semantic translation are two major translation methods put forward by Peter Newmark in one of his masterpieces Approaches to Translation. Meanwhile, he classified the texts into three types according to their functions, namely, expressive, informative as well as vocative texts, and accordingly explored the adoption of ST or CT from the perspective of the dominant function of the text. However, the present paper takes a new look into the theory of ST and CT by analyzing them in terms of syntax, culture and pragmatics, which can shed some light on translating practice. The conclusion is that the combination and flexible use of both is the most ideal translation method.
\end{abstract}

\section{Introduction}

In the book Approaches to Translation, Peter Newmark put forward his theory of semantic translation (ST) and communicative translation (CT) and classifies texts into the following three types: expressive, informative and vocative texts. Generally speaking, he explains and distinguishes the two methods that ST focuses on the semantic content of translation while CT on the effect or results of translating. Meanwhile, centered on the analysis of text types, he holds that semantic translation is generally applied in expressive texts and communicative translation is in informative and vocative texts, which has provided a useful perspective to the issue of translation.

The present paper takes a new look into the theory of ST and CT by analyzing them in terms of syntax, culture and pragmatics, from which conclusion and strategies are brought out respectively for the purpose of dealing with various kinds of situations in translation. It also theoretically and practically sheds light on the improvement of the quality of translation and the promotion of cross-cultural communication.

\section{Contrast and comparison between Semantic Translation and Communicative Translation}

Peter Newmark says that "the concepts of communicative and semantic translation represent my main contribution to general translation theory" [1]. He classifies the types of texts into expressive function, informative function and vocative function, and puts forth the above two corresponding translation methods, namely, CT and ST, for different types of texts. And the main difference between ST and CT concluded from Approaches to Translation can be summarized in the following table: 
Table 1: A comparison between ST and CT

\begin{tabular}{|l|l|}
\hline Semantic translation(ST) & Communicative translation(CT) \\
\hline Author-centered & Reader-centered \\
\hline $\begin{array}{l}\text { Semantic- and syntactic-oriented. Length of sentences, } \\
\text { position and integrity of clauses, word position, etc. } \\
\text { preserved whenever possible. }\end{array}$ & $\begin{array}{l}\text { Effect-oriented. Formal features or original sacrificed } \\
\text { more readily. }\end{array}$ \\
\hline $\begin{array}{l}\text { Usually more awkward, more detailed, more complex, but } \\
\text { briefer. }\end{array}$ & $\begin{array}{l}\text { Easy reading, more natural, smoother, simpler, clearer, } \\
\text { more direct, more conventional, conforming to } \\
\text { particular register of language but longer. }\end{array}$ \\
\hline Source language biased. & Target language biased. \\
\hline Always inferior to the original because of loss of meaning. & $\begin{array}{l}\text { May be better than original because of gain in force and } \\
\text { clarity, despite loss in semantic content. }\end{array}$ \\
\hline Out of time and local place-"eternal" & Ephemeral and rooted in its context, "existential". \\
\hline The translator has no right to improve or to correct. & $\begin{array}{l}\text { The translator has the right to correct and improve the } \\
\text { logic and style of the original, clarify ambiguities, } \\
\text { jargons, normalize bizarre personal usage. }\end{array}$ \\
\hline $\begin{array}{l}\text { Unit of translating: tends to words, collocations and } \\
\text { clauses. }\end{array}$ & Unit of translating: tends to sentences and paragraph. \\
\hline Basically the work of translating is an art. & Basically the work of translating is a craft. \\
\hline Usually the work of one translator. & Sometimes the product of a translation team. \\
\hline Meaning & Message \\
\hline
\end{tabular}

The above table clearly demonstrates the great differences between ST and CT. ST focuses mainly on the semantic content of the source text while CT focuses essentially on the comprehension of the receptors. Newmark points out that one basic difference between them is that "where there is a conflict, the communicative must emphasize the "force' rather than the content of the message" [2]. As for the comparison between ST and CT, the two translation methods bear some overlapping elements, which means that they may take the same effect when the text conveys a general rather than a culturally bound message. In a word, any successful translation is a combination of the two methods. It is only a matter of choice. Only the flexible use of both is the most ideal translation method.

\section{A Brief Analysis of ST and CT though Examples}

In view of the features of the two methods, it is necessary to apply them in the translating practice to look at how well they work in different situations. In this part, CT and ST are applied to down-to-earth translation examples and analyzed at the level of syntax, culture and pragmatics.

\subsection{Analysis at the level of syntax}

Language is a device of mutual understanding as well as communication and presents certain social and cultural elements as well. Each language boasts its own characteristics and unique way of expression. Chinese and English are no exceptions since they belong to different language systems resulting from the different geographical environment, national customs, values, literary traditions and way of thinking.

As for the aspect of syntax, the prominent difference lies in parataxis vs hypotaxis. Chinese is parataxis, that is, the words and sentences are organized loosely by semantic. By contrast, English is hypotaxis with the help of overt cohesion. Chinese stresses on functions and meaning, while English focuses on structure.

An example is derived from the speech made by the former Premier Zhu Rongji in a press conference:

The devaluation of RMB will further hit the economies of South East Asia, and provoke another round of devaluation. So there will be no end to this process and both sides will be hurt in the final analysis.

Constant repetition and the lack of overt cohesion are accepted and understandable in the Chinese version. However, if the original text is translated with the use of ST, the English equivalence would be full of redundancy and misunderstanding since ST demands a possible preservation of the syntactic structure. Instead, how the above English equivalence handled the repetition was to omit it and the interpreter also rendered the representation structurally linear with the help of cohesive devices like "so" "both" and "and", which accorded with the English way of expression as a result of the use of CT

Due to the difference between Chinese and English in ways of expression, sentence structure, text texture and logic, the choice for any of the two translation methods depends, to a large extent, on the 
features of the source text. ST is adopted with the source text of a written-like or well-organized logical structure. Otherwise, for the convenience of understanding and avoidance of semantic vagueness, CT makes more sense.

\subsection{Analysis at the level of culture}

Different nations, with different history, politics, economy, social development and particular cultural tradition, have different ways of thinking and cultural psychology, which are presented by their own language. Thus, language serves as a sign system and a carrier of culture. In this case, translation, an issue dealing with language communication, has close relationship with culture. "For truly successful translating, biculturalism is even more important than bilingualism. Since words only have meanings in terms of the cultures in which they function" [3].

Religion is an indispensable part of culture. For instance, from the Middle Ages, Christianity, as a cultural carrier, has connected the whole Europe and accordingly, it has largely contributed to forming the unique western culture. Buddhism, one of the world's four major religion ruling China for thousands of years, also contributed to the formation of the unique oriental culture. Under the different religious background between the source text and target text, The Story of the Stone or A Dream of Red Mansions was translated by David Hawkes and the couple Yang Xianyi as well as Dai Naidie respectively since the former adopts CT and the latter adopts ST.

In the first chapter of A Dream of Red Mansions, "All men long to be immortals." [4]and "All men know that salvation should be won." [5]by Yang Xianyi and David Hawkes respectively. Immortals is that is translated by Yang since it is a term in Taoism. Becoming an immortal is the highest ideal in Taoism. By contrast, Hawkes resorts to "salvation", a concept in Christianity. It's a Christian creed that one can be saved from the sin. Thus, it is clearly showed that Yang Xianyi keeps the Taoist philosophy and chooses to be loyal to the source text. In contrast, Hawkes lays more emphasis on the readers' religious background and psychology.

Generally speaking, CT can transfer the underlying meaning, especially that in the cultural aspect while ST can also enrich the TL by introducing the foreign cultural elements, through which people can get a glimpse of the culture in the SL. Translation itself is not the aim of translation, the purpose of translation lies in transferring effective information, namely, the information the speaker intends to convey or the audience expect to get. And this is also the reason for the need of different translating strategies when discussing CT and ST in terms of culture. If the speaker and the audience share the same cultural knowledge, it is practical to resort to ST, or the interpreter has to resort to CT by explaining them in order to bridge the cultural gap. What is more, their explanation is supposed to aim at conveying meaning disregarding the form. Just as Peter Newmark points, in A Textbook of Translation, "There should be no loss of meaning, and the aim, which is often realized".

\subsection{Analysis at the level of pragmatics}

"Pragmatics is viewed as the study of people's comprehension and production of linguistic action in context. The associations attached to the word are its connotative meaning, and the meaning of a word varies and is 'conditioned' by its context" [6]. In this case, from the perspective of pragmatics, context plays an important role when the translators deal with the choice between CT and ST since "context can be common knowledge or encyclopedic knowledge; it is always a basis for mutual understanding" [7].

The following Chinese style of slogans can often be heard via TV on the occasion of a parade. Those words can be interpreted as follows: "Hello, comrades!", "Hello, leader" and "comrades, you have worked hard!". Although the three sentences have no errors of lexicon, syntax or semantics, the audience without any contextualized knowledge will necessarily construe them like these, especially the last two lines.

The original translated version, of course, turns a blind eye to the solemn context. To make it follow the original meaning of the source text, the context is supposed to be strategically embedded into the English equivalence like this: The chairman greets the soldiers and the soldiers salute the chairman. This version of translation is simpler and it conveys the equivalent communicative function. Thus, viewed from the approach of ST and CT, it is CT of course. 
Since pragmatics is "a science about how people deal with the aspects of language going beyond the simple meaning of what people hear and say" [8], the pragmatic meaning is supposed to be conveyed and translated with the consideration of context. Thus, as an effect-oriented method, CT serves as the priority for the translators to take the underlying meaning and pragmatic effect into full play.

\section{Conclusion}

The theory of ST and CT arouses great attention in translation academic since its coming into being. Different from the perspective of the text type, the present paper takes syntax, culture and pragmatics into account.

From the foregoing discussion of CT and ST, it is apparent to see that translation is a very difficult and complicated process which involves lots of things such as syntax, culture and pragmatics. Apart from translation purposes, intended audiences and text types, etc., the above three factors, namely, syntax, culture and pragmatics, are also supposed to be considered in translation when the translators set out to translate and make the choice of translation methods.

With the conclusion and strategies brought out for the above three aspects respectively, the present paper hopes to perfect the theory of ST and CT and provide guidance for the translators through applications in practical translation and accordingly, the theory will necessarily be continually revised and improved to conform to advances in translation studies.

Therefore, just as Newmark himself commented in A Textbook of Translation, "there is no one communicative nor one semantic method of translating a text - these are in fact widely overlapping bands of methods. A translation can be more, or less, semantic - more, or less, communicative - even a particular section or sentence can be treated more communicatively or less semantically" (40). Thus, the interpreter's choice for CT and ST was subject to the importance of the original utterance for the speaker's expectation, that is, the more important the original utterance for the speaker is, the more emphases are placed on ST, and vice versa. In a nutshell, the translator is expected to use the two methods flexibly with a combination of both to achieve the ideal translation.

\section{References}

[1]. Newmark, Peter. Approaches to Translation. Shanghai: Shanghai Foreign Language Education Press, 2001.

[2]. Newmark, Peter. A Textbook of Translation. London: Prentice Hall International Ltd, 1988.

[3]. Nida, Eugene A. Language, Culture and Translation. Shanghai: Shanghai Foreign Language Education Press, 1993.

[4]. Yang, Xianyi. A Dream of Red Mansions. Beijing: The Foreign Language Press, 1978.

[5]. David, Hawkes. \& John, Minford. The Story of the Stone. London: Penguin Books, 1986. [2]

[6]. Hu, Zhuanglin. Linguistics: A Course Book. Beijing: Beijing University Press, 2006.

[7]. Riccardi, Alessandra. Translation Studies: Perspectives on an Emerging Discipline. Cambridge: Cambridge University Press, 2002.

[8]. Munday, Jeremy. \& Hatim, Basil. Translation: an Advanced Resource Book. London: Taylor \& Francis Group, 2004. 